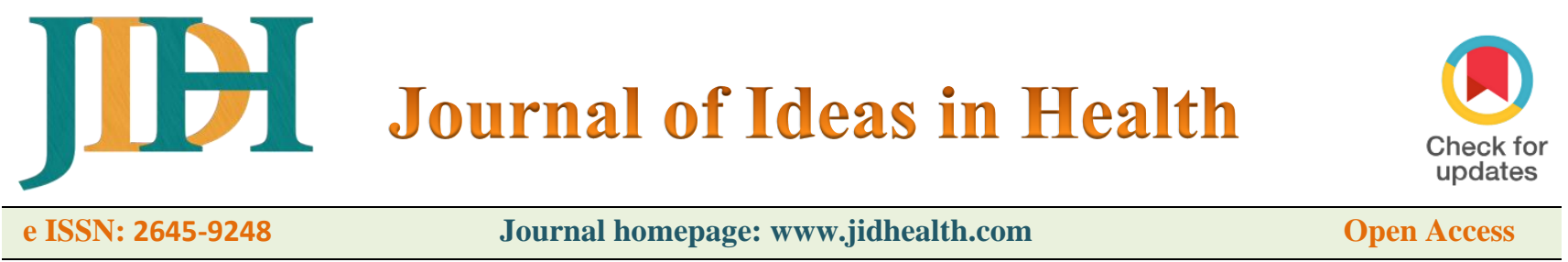

Original Article

\title{
Patient satisfaction in outpatient medical care: the case of Iraq
}

\author{
Saad Ahmed Ali Jadoo ${ }^{1 *}$, Shukur Mahmood Yaseen², Mustafa Ali Mustafa Al-Sammarrie ${ }^{3}$, Anmar \\ Shukur Mahmood ${ }^{4}$
}

\begin{abstract}
Background: Healthcare providers are increasingly interested in patient satisfaction as an indicator to assess the quality of health services. This study investigates the level of satisfaction among Iraqi patients attending the outpatient (OP) clinic.

Methods: This was a cross-sectional study conducted from October to December 2019 among outpatient attendees in two busiest centers in Iraq. A convenience sample of 235 (response rate of $88.0 \%$ ) completed the self-administered short-form patient satisfaction questionnaire (PSQ-18). The independent variables included socio-demographic, economic, and self-perceived health status. Data were analyzed in SPSS, where descriptive analysis (mean \pm standard deviation) and univariate (independent sample t-test, ANOVA test) and multivariate linear regression "Enter technique" was done at 0.05 level of significance and $95 \%$ confidence interval.

Results: The mean age of respondents was 39.3 ( \pm 14.8$)$. The sample was mostly women $(55.3 \%)$, and $37.4 \%$ in the age group of $30-49$ years. More than half of participants residing in the urban regions $(54.5 \%)$ from families of monthly household income less than 500,000 Iraq Dinars (USD 400). However, the majority (70.6\%) have the first visit to the OP clinic, and $53.6 \%$ self-perceived health as good or very good. Results of multiple linear regression showed that patients residents in rural regions $(B=5.4, P<0.001)$, married $(B=4.8, P<0.001)$, unemployed $(B=$ 4.7, $P<0.001)$ and low educated $(B=1.5, P<0.051)$ exhibited higher service satisfaction score compared to urban residents, single, employed and high educated participants respectively. However, patients aged fifty years and more $(B=-2.1, P<0.001)$ and those with poor health $(B=-2.5, P<0.001)$ exhibited lower service satisfaction scores compared to young age patients and the healthy participants, respectively.
\end{abstract}

Conclusion: The high demand for the use of health resources in metropolitan cities by the rural population indicates inequality in the distribution of health services and an increase in the rural-to-urban displacement.

Keywords: Outpatient, Satisfaction, PSQ-18, Iraq

\section{Background}

Among many services presented by health care providers, outpatient clinics sound to have some peculiarities, having the most significant percentage of people, the shortest time for the visit, and the least intervention [1]. Nonetheless, it remains one of the most critical measures for quality of service, whether in the primary healthcare clinics or outpatient clinics of the general hospitals [2]. Among reliable tools of assessment is patient satisfaction. Indeed, it highly varies within societies (inter-variation) and even within the same society (intra-

*Correspondence: drsaadalezzi@gmail.com

${ }^{1}$ Department of Public Health, Faculty of Medicine, Bezmialem Vakif University, Istanbul, Turkey

Full list of author information is available at the end of the article variation), but it tends toward the poor score in particularly in the middle and lower-income countries (MLIC) [3]. In Iraq, the health system has been systematically destroyed since the USDespite spending tens of billions of US dollars over the past seventeen years, the Iraqi citizen did not see any development in the health system compared to neighboring countries or even countries that do not have such wealth as Iraq [5,6]. The main occupation forces (the American and British) did not present any definite plans to reform the health system. On the contrary, the competent Iraqi administrations were deliberately replaced with others proven to be corrupt for all $[4,6,7]$. Therefore, the level of patient satisfaction in Iraq is expected to be worse [5], probably because of the internal conflicts, weak national health system, and inadequate support (financial and logistic) to the health institutions [8]. Obviously, there is an unbalance between the available physicians (low) and the number of visitors to 
outpatient clinics (high) [4,8]. Moreover, insufficient drugs and laboratory investigations add more burden. Ultimately, the client's trust in this service was noticeably affected [5,7]. Although this assessment of satisfaction is continuously done worldwide, it is hardy to be done in Iraq. This study aimed to assess the patients' satisfaction toward the outpatient clinic services in two busiest centers in the middle of Iraq.

\section{Methods}

Study design

A cross-sectional study was conducted from October to December 2019 at the outpatient medical care of Baquba Teaching Hospital (Diyala Province), and Samarra Hospital (Salah al Din Province) in Iraq. A self-administered questionnaire was distributed among patients receiving clinical consultations and treatment at outpatient clinics. A well-trained data collectors' team was recruited to collect the data using a convenience sampling technique. Iraqi citizen aged 18 years and more willing to participate, and successfully finished the outpatient healthcare visit have included. Severely illness, illiterate patients, unwilling to participate, healthcare professional have excluded. The sample size was calculated to be 267 based on $50.0 \%$ expected prevalence rate of health service satisfaction [9] and 0.05 level of accuracy with a confidence interval of $90 \%[10,11]$. Twenty-one questionnaires were excluded due to exclusion criteria (Table 1) and the missing data. The total response rate was $88.0 \%$ (235/267).

\section{Study tool}

The study instrument consists of three parts. The first part included items on sociodemographic factors (gender, age, and marital status). The second part included the patients' socioeconomic and health characteristics (household income, employment status, education level, type of residence, overall health perception, and purpose of visit to the clinic). The third part was the Short-Form Patient Satisfaction Questionnaire (PSQ-18). The PSQ-18 was developed by Marshall and Hays [12] to explore patient satisfaction towards healthcare service in various clinical settings, including outpatient departments.

PSQ-18 is comprised of eighteen items with seven dimensions. These items were scored on a five-point Likert scale ranging from one (strongly agree) to five (strongly disagree). As reported by Marshal and Hyas [12], some elements of PSQ-18 are formulated to reflect satisfaction with medical care, while others are formulated to reflect dissatisfaction. Therefore, the scores of "1,2,3,5,6,8,11,15,18" items have been reversed to obtain the total satisfaction score [12]. However the seven subscales are yielded by averaging the score of the related items as follows: the General satisfaction (3rd and seventeenth items), technical quality (second, fourth, sixth and fourteenth items), interpersonal manner (tenth and eleventh items), communication (first and thirteenth items), financial aspects (fifth and seventh items), time spent with the doctor (twelfth and fifteenth items), and accessibility and convenience (eighth, ninth, sixteenth and eighteenth items) [12]. The PSQ-18 questionnaire was forward-backward translated into Arabic by two academic and linguistic experts. The instrument was pilot-tested with fifteen participants (not included in the study). Content validity (CV) was performed using the technique of the content validity rate (CVR) [13]
Statistical analysis

The data were entered and analyzed using the Package for Social Sciences (SPSS) (version 16.0, IBM, Armonk, NY). All variables were subjected to descriptive analysis.

The internal consistency of the scale was tested using Cronbach's alpha. PSQ-18 scores were presented as mean and standard deviations. The total satisfaction scores were tested for normality. An independent student $t$-test and ANOVA test were recruited to compare the overall score of patient satisfaction across different study variables. The post hoc test was used to determine where the significant difference was in the ANOVA test. The "Enter" technique was considered to obtain the significant factors associated with patient satisfaction scores in multiple linear regression analysis. Multicollinearity was checked between independent variables, and the accepted level of significance was set below $0.05(P<0.05)$.

\section{Results}

Sample Characteristics

A total of two hundred and thirty-five patients. The mean $( \pm \mathrm{SD})$ age of the patients was $39.3( \pm 14.8)$ years, and the majority 88 $(37.4 \%)$ were in the age group of 30-49 years. More than half of respondents were females $(130,55.3 \%)$, married $(126,53.6 \%)$, unemployed $(121,51.5 \%)$, low education $(136,57.9 \%)$ and residing in the rural regions $(128,54.5 \%)$. Most of the patients $164(74.0 \%)$ with a monthly household income of less than 500,000 Iraq Dinars (IQD) which equivalent to USD 400. Most patients perceived a "good" health status 105 (43.8\%), and the majority came to the clinic for "new visit" $(166,70.6 \%)$ (Table $1)$.

Table 1 Patient characteristics $(n=235)$

\begin{tabular}{|c|c|c|c|}
\hline Characteristics & Category & $\mathrm{N}$ & $\%$ \\
\hline \multirow[t]{2}{*}{ Gender } & Female & 130 & 55.3 \\
\hline & Male & 105 & 44.7 \\
\hline \multirow[t]{3}{*}{ Age (years) } & $<30$ & 82 & 34.9 \\
\hline & $30-49$ & 88 & 37.4 \\
\hline & $>50$ & 65 & 27.7 \\
\hline \multirow[t]{2}{*}{ Marital status } & Single & 109 & 46.4 \\
\hline & Married & 126 & 53.6 \\
\hline \multirow[t]{2}{*}{ Employment } & Employed & 121 & 51.5 \\
\hline & Unemployed & 114 & 48.5 \\
\hline \multirow{4}{*}{$\begin{array}{l}\text { Monthly household } \\
\text { income (USD*) }\end{array}$} & $<200$ & 64 & 27.2 \\
\hline & $200-399$ & 110 & 46.8 \\
\hline & $400-1000$ & 44 & 18.7 \\
\hline & $>1000$ & 17 & 7.2 \\
\hline \multirow[t]{2}{*}{ Education level } & High education & 136 & 57.9 \\
\hline & Low education & 99 & 42.1 \\
\hline \multirow[t]{2}{*}{ Residence } & Rural & 128 & 54.5 \\
\hline & Urban & 107 & 45.5 \\
\hline \multirow{4}{*}{$\begin{array}{l}\text { Overall health } \\
\text { perception }\end{array}$} & Very good & 23 & 9.8 \\
\hline & Good & 103 & 43.8 \\
\hline & Middle-acceptable & 85 & 36.2 \\
\hline & $\mathrm{Bad}$ & 24 & 10.2 \\
\hline \multirow[t]{2}{*}{ Purpose of visit } & New visit & 166 & 70.6 \\
\hline & Follow up & 69 & 29.4 \\
\hline
\end{tabular}

*1 USD=Iraqi Dinar 1200 (Exchange in December 2019) 
Patient satisfaction with outpatient medical care

Table 2 presents the patient satisfaction score with outpatient medical care. Cronbach's alpha values for the seven subscales of PSQ-18 had values ranging between 0.71 and 0.79 . The mean $( \pm$ SD) of patient satisfaction score was the highest in terms of institutional factors, particularly "technical quality" $(15.4 \pm 2.8)$ and was the lowest in terms of general satisfaction towards healthcare service acquired by patients $(5.8 \pm 1.8)$. The mean $( \pm \mathrm{SD})$ of the total satisfaction score was $61.5 \pm 9.2$, and the score ranged between 32 and 89 .

Association between sample characteristics and outpatient medical care satisfaction

There was a statistically significant difference between groups determined by one-way ANOVA $(\mathrm{F}(2,27)=36.392, P=$ $<0.001)$. A Tukey post hoc test revealed that patients aged less than 30 years $(64.4 \pm 8.0)$ and patients aged $30-49$ years $(64.2 \pm$ 7.5) perceived higher service satisfaction in comparison to patients aged 50 years and more $(54.3 \pm 8.8, P=0.005)$ and (54.3 $\pm 8.8, P=0.001)$ respectively. However, there was no statistically significant difference between patients aged less than 30 years, and patients aged $30-49$ years $(P=0.989)$.

Married patients exhibited higher service satisfaction (66.1 \pm 7.2) than single patients $(56.3 \pm 8.5)(P<0.001)$. Unemployed patients exhibited higher service satisfaction $(67.4 \pm 6.0)$ than employed patients $(56.0 \pm 8.2)(P=0.001)$. Patients with low education exhibited higher service satisfaction $(63.5 \pm 9.0)$ than high education $(60.1 \pm 9.1)(P=0.005)$. Patients resident in rural region exhibited higher service satisfaction $(67.9 \pm 6.7)$ than urban residents $(56.2 \pm 7.5)(P<$
0.001). There was no statistically significant difference between genders $(\mathrm{p}=0.281)$ and the purpose of the visit $(P=0.110)$ and health service satisfaction.

There was a significant association between self-perceived health status and the health service satisfaction $(P<0.001)$; a post hoc test revealed that patients who perceived very good health exhibited higher service satisfaction $(68.9 \pm 8.8)$ in comparison to patients perceived good health $(63.0 \pm 8.4, P=$ $0.019)$, acceptable health $(59.4 \pm 7.9, P<0.001)$, and bad health (55.4 $\pm 11.1, P<0.001)$. Moreover, a post hoc test revealed that patients who perceived good health exhibited higher service satisfaction $(63.0 \pm 8.4))$ in comparison to patients perceived acceptable health $(59.4 \pm 7.9, P=0.024)$, and bad health $(55.4 \pm$ 11.1, $P<0.001)$. There was no statistically significant difference between acceptable and bad health $(P=0.188)$ (Table $3)$. There was a significant association between monthly income and the health service satisfaction $(P<0.001)$; a post hoc test revealed that patients who received income of more than US\$ 1000 exhibited higher service satisfaction $(67.5 \pm 9.7)$ in comparison to patients received less than USD 200 (58.4 \pm 9.7 , $P<0.001)$, and the patients who received USD 200-400 (60.6 \pm $8.8, P=0.013)$. Moreover, a post hoc test revealed that patients who received USD 400-1000 exhibited higher service satisfaction $(66.1 \pm 7.0))$ in comparison to patients who received less than USD $200(58.4 \pm 9.7, P<0.001)$, the patients who received USD 200-400 $(60.6 \pm 8.8, P=0.003)$. However, there was no statistically significant difference between the patients who received USD 1000 and who received USD 400$1000(P=0.941)$, and also there was no statistically significant difference between the patients who received less than USD 200 and who received USD 200-400 ( $P=0.407)$ (Table 3).

Table 2 Subscale reliability of PSQ-18 and health service satisfaction scores $(n=235)$

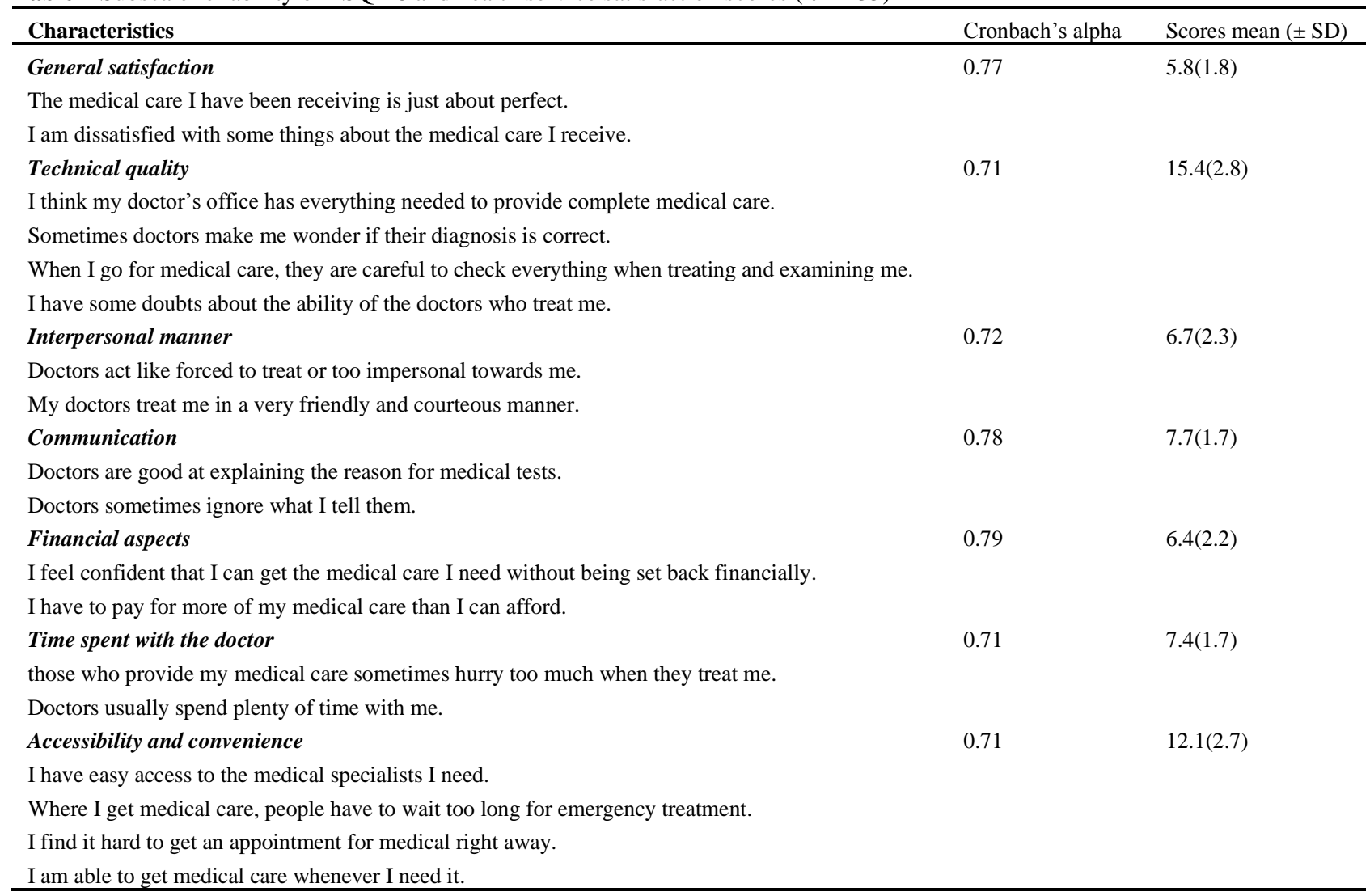


Factors associated with outpatient medical care satisfaction among patients by multiple linear regression

Patients aged 50 years and more had, on average, 2.1 (95\% CI3.1-1.1) lower service satisfaction scores as compared to young age patients $(P<0.001)$. The married patient had, on average, 4.8 (95\% CI 3.2- 6.4) higher service satisfaction scores as compared to single (unmarried, divorced, and widow) ( $P$ $<0.001)$. The unemployed patient had on an average $4.8(95 \%$ CI 3.0-6.5) higher service satisfaction score as compared to employed $(P<0.001)$. The low educated patient had, on average, $1.5(95 \%$ CI $0.01-3.0)$ higher service satisfaction compared to the higher educated patient $(P=0.051)$. Patients who perceived health as not good had, on average, 2.5 (95\% CI3.4-1.6) lower service satisfaction compared to patients who perceived health as good and very good $(P<0.001)$. Patients residents in rural regions had, on average, 5.4 (95\% CI 3.4-7.2) higher service satisfaction compared to the residents in the urban region $(P<0.001)$ (Table 4$)$.

Table 3 Association between sample characteristics and health service satisfaction $(n=235)$.

\begin{tabular}{|c|c|c|}
\hline Characteristics & Mean (SD) & P-value \\
\hline Gender & & 0.281 \\
\hline Female & $62.1(8.8)$ & \\
\hline Male & $60.8(9.7)$ & \\
\hline Age (years) & & $<0.001$ \\
\hline$<30$ & $64.4(8.0)$ & \\
\hline $30-49$ & $64.2(7.5)$ & \\
\hline$\geq 50$ & $54.3(8.8)$ & \\
\hline Marital status & & $<0.001$ \\
\hline Married & $56.3(8.5)$ & \\
\hline Single & $66.1(7.2)$ & \\
\hline Employment & & $<0.001$ \\
\hline Unemployed & $56.0(8.2)$ & \\
\hline Employed & $67.4(6.0)$ & \\
\hline Monthly household income & & $<0.001$ \\
\hline$<200$ & $58.4(9.7)$ & \\
\hline 200-399 & $60.6(8.8)$ & \\
\hline $400-1000$ & $66.1(7.0)$ & \\
\hline$>1000$ & $67.5(8.1)$ & \\
\hline High education level & & 0.005 \\
\hline Low education & $60.1(9.1)$ & \\
\hline High education & $63.5(9.0)$ & \\
\hline Residence & & $<0.001$ \\
\hline Urban & $56.2(7.5)$ & \\
\hline Rural & $67.9(6.7)$ & \\
\hline Overall health perception & & 0.001 \\
\hline Very good & $68.9(8.8)$ & \\
\hline Good & $63.0(8.4)$ & \\
\hline Middle-acceptable & $59.4(8.0)$ & \\
\hline Bad & $55.4(11.1)$ & \\
\hline Purpose of visit to the clinic & & 0.110 \\
\hline New visit & $60.9(9.4)$ & \\
\hline Follow up & $63.0(8.4)$ & \\
\hline
\end{tabular}

\section{Discussion}

Outpatient consulting clinics represent the most prominent arms of public health services in Iraq. The outpatient clinics attract a high percentage of patients, especially those with limited incomes. In the current study, the authors aimed to explore the factors affecting patient satisfaction with the busiest outpatient medical centers. Similar to earlier studies [9] and inconsistent with original psychometric properties concluded by Marshall and Hays [12], the Cronbach's alpha values of the PSQ-18 subscales had values greater than 0.70 suggesting an acceptable internal consistency.

In the final model, patients aged fifty years and more, married, unemployed, low education in a rural region, and those selfperceived health statuses as not good, exhibited significant associations with patient satisfaction scores.

In this study, patients residing in rural regions exhibited the highest service satisfaction, followed by married and unemployed patients. The rural residents are five and half times $(\mathrm{B}=5.4, P<0.001)$ more satisfied with $\mathrm{OP}$ health services than the urban residents. The adoption of wrong policies for health management since 2003 has negatively reflected on the quality and continuity of health services provided in Iraq [5,7]. Most of the districts, villages, or human communities, far from the city center, lack basic health services, especially specialized ones [14]. Moreover, most of the study sample was from areas prone to armed conflict, which caused large waves of internal displacement. The extension of the displacement periods for years led to great demographic changes and the mixing of rural and urban residents and vice versa. Therefore, most rural populations tend to contact the OP clinics of public hospitals in big cities. A state of undeclared competition emerged between urban and rural residents to benefit from health care services. In the absence of suitable alternatives, dissatisfaction with health services among urban residents was evident. The lack of medical services in the countryside may be considered one of the main weaknesses in managing the security, services, and reconstruction files in conflict-affected areas. Ali jadoo et al. [15] and Al-Samarrai et al. [16] found that most of the IDPs have refused to return to their homes due to the security situation and lack of services.

Previous studies indicated that accessing the required health care among the rural population was more difficult compared to urban areas $[17,18,19]$. Other studies have discussed the difference between rural and urban residents regarding expectations and utilization of health care services [20,21] and the differences in the level of satisfaction [22,23]. However, the level of expectations towards quality of care was higher among urban residents [24,25].

Besides, this study showed that the unemployed respondents are five times $(\mathrm{B}=4.746, \mathrm{P}<0.001)$ more satisfied with $\mathrm{OP}$ health services than the employed. However, there was no difference between high or low-income people. It may be related to the economic situation, the nature of society, the demographic composition in Iraq, and the ability to adapt after displacement. Furthermore, the society in Iraq is characterized by male dominance, a high rate of early marriage, and a big family with an average of seven members, especially in the countryside [26]. The greater the number of family members, the less labor is needed on the farm. Outpatient clinics are sometimes the best choice for families with limited income because they prioritize spending on housing or food overspending on health [27,28]. However, the educational opportunities are less compared to cities, and thus the percentage of unemployed is higher. 
Table 4 Factors associated with health service satisfaction among patients by multiple linear regression $(n=235)$

\begin{tabular}{llllcc}
\hline Predictors & B & Std. Error & Beta & P-value & 95\% CI lower-upper \\
\hline Age group ( $\geq 50$ years) & -2.103 & 0.495 & -0.181 & $<0.001$ & $<0.001$ \\
Marital Status (married ) & 4.816 & 0.800 & 0.262 & $<.1-1.1$ \\
Employment Status (Unemployed) & 4.746 & 0.909 & 0.259 & $<0.001$ & 0.051 \\
Education Level (low) & 1.448 & 0.740 & 0.078 & $<0.001$ & $-0.01-3.0$ \\
Self-Assessment of Health (not good) & -2.504 & 0.459 & -0.220 & $-3.4-1.6$ \\
Place of Residency (rural ) & 5.338 & 0.925 & 0.290 & $<0.001$ \\
\hline
\end{tabular}

Moreover, the low educated people are one and half times $(\mathrm{B}=1.5, \mathrm{P}=0.051)$ more satisfied with outpatient clinics than high educated people because they are less aware of their rights on the quality of medical services. There is much evidence that a low level of education and poor economic resources are associated with patient satisfaction [17, 23, 29].

Unlike to findings of previous studies conducted in Malaysia [9], China [17], Pakistan [29] respondents aged fifty years and more $(\mathrm{B}=-2.103, P<0.001)$ and those who perceived their health as poor $(\mathrm{B}=-2.504, P<0.001)$ are about two times and a half less satisfied with outpatient clinics services than healthy and younger age groups. Most of the older people suffer from chronic diseases and thus describe themselves as poor health. The older people are more likely to be less oriented towards the state of health institutions in Iraq (i.e., expecting optimal services), and therefore, dissatisfaction is often linked to the access and quality of health care available to them. Kelly et al. [30] pointed out that the elderly has a general feeling of neglect, especially concerning health care.

Additionally, gender has no impact on the level of satisfaction towards the OP healthcare services. However, previous studies reported a relationship between patient satisfaction and gender; Woods and Heidari [31] found that females were less satisfied than males; while Chandra et al. [32] found that females expressed higher satisfaction toward OP department compared to their counterpart male patients.

This study's results were consistent with that conducted in Baghdad (capital of Iraq) regarding antenatal care. Similarly, low educated and unemployed showed high satisfaction. However, the old age women were more satisfied with the accessibility and services provided in primary healthcare centers [33]. Our study's findings were supported by the results of a study conducted in Erbil (North of Iraq) [34]. The authors found no gender differences regarding satisfaction levels, and satisfaction was high among low-income patients. However, patients aged forty and more were more satisfied than the younger age group. Moreover, our results were inconsistent with that reported by a study conducted in Karbala (South of Iraq) [35]. Authors found women more satisfied than men in most of the health services in the primary healthcare center.

Most of the previous studies were conducted in areas such as Baghdad [33], Northern [34], and Southern [35,36] of Iraq, where the security situation and the level of health services were acceptable. Therefore, the respondents rated the satisfaction moderate to a high level. In contrast, our respondents belong to the central and western regions, subjected to successive waves of armed violence, and forced displacement, with insecurity and lack of services $[15,16,37]$
This study complained about some limitations. Although the data were collected from the outpatient department of major hospitals in two different provinces, however, the results cannot be generalized, but it can represent the case of the middle region of Iraq where the information was collected. Cross-sectional studies do not allow establishing a causal relationship between the variables as in this study.

\section{Conclusion}

Patient satisfaction was the highest in terms of institutional factors, particularly "technical quality" and "accessibility and convenience," but satisfaction was the lowest in terms of general satisfaction towards healthcare service. Patients in the age group of fifty years and more, married, unemployed, low educated, self-perceived bad health, and the rural residents were significantly related to patient satisfaction. Any efforts made to enhance patient satisfaction must be directed towards reducing the consumption of outpatient clinics in public hospitals by improving the primary healthcare services in the rural areas and activating the family doctor's system throughout the country.

\section{Abbreviation}

OP: Outpatient; MLIC: the middle and lower-income countries (MLIC); PSQ: Patient Satisfaction Questionnaire; CV: Content Validity; CVR: Content Validity Rate; SPSS: Package for Social Science; USD: United States Dollar; IQD: Iraqi Dinar; M: Mean; SD: Standard Deviation

\section{Declarations}

\section{Acknowledgement}

We render our thanks to the team who participated in the data collecting process for their time and unlimited support.

\section{Funding}

The author received no financial support for the research, authorship, and/or publication of this article.

Availability of data and materials

Data will be available by emailing drsaadalezzi@gmail.com

\section{Authors' contributions}

SAAJ is the principal investigator of the study who designed the study and coordinated all aspects of the research including all steps of the manuscript preparation. He is responsible for the study concept, design, writing, reviewing, editing, and approving the manuscript in its final form. SMY, MAA, and ASM contributed to the collecting the data, analysis, and interpretation of data, drafting the work, writing the manuscript, and reviewed and approved the manuscript. All authors read and approved the final manuscript. 
Ethics approval and consent to participate

We conducted the research following the Declaration of Helsinki, and the protocol was approved by the Ethic Committee of Faculty of Medicine, University of Diyala, Iraq (Ref: 1023 at 26-March-2019). Moreover, written informed consent was obtained from each included patient who were willing to participate after explanation of the study objectives and guarantee of secrecy.

Consent for publication

Not applicable

Competing interest

The authors declare that they have no competing interests.

\section{Open Access}

This article is distributed under the terms of the Creative Commons Attribution 4.0 International License (http://creativecommons.org/licenses/by/4.0/), which permits unrestricted use, distribution, and reproduction in any medium, provided you give appropriate credit to the original author(s) and the source, provide a link to the Creative Commons license, and indicate if changes were made. The Creative Commons Public Domain Dedication waiver (http://creativecommons.org/publicdomain/zero/1.0/) applies to the data made available in this article, unless otherwise stated.

Author details

${ }^{1}$ Department of Public Health, Faculty of Medicine, Anbar University, Anbar, Iraq. ${ }^{2}$ Department of Anatomy, Molecular Genetics, Faculty of Medicine, University of Diyala, Diyala, Iraq. ${ }^{3}$ Department of Family and Community Medicine, Faculty of Medicine, Anbar University, Anbar, Iraq. ${ }^{4}$ Faculty of Computer Engineering, Altinbas University, Istanbul, Turkey

Article Info

Received: 01 May 2020

Accepted: 07 June 2020

Published: 26 August 2020

\section{References}

1. Johannessen KA, Alexandersen N. Improving accessibility for outpatients in specialist clinics: reducing long waiting times and waiting lists with a simple analytic approach. BMC Health Serv Res 2018;18: 827. https://doi.org/10.1186/s12913-018-3635-3

2. Chakravarty A. Evaluation of service quality of hospital outpatient department services. Med J Armed Forces India. 2011;67(3):221224. https://doi:10.1016/S0377-1237(11)60045-2

3. Al-Abri R, Al-Balushi A. Patient satisfaction survey as a tool towards quality improvement. Oman Med J. 2014;29(1):3-7. https://doi.org/10.5001/omj.2014.02

4. Ali Jadoo SA, Aljunid SM, Dastan I, Tawfeeq RS, Mustafa AM, Ganasegeran K, Al Dubai SAR. Job satisfaction and turnover intention among Iraqi doctors - a descriptive cross-sectional multicentre study. Hum Resour Health 13, 21 (2015). https://doi.org/10.1186/s12960-015-0014-6

5. Aboulenein A, Levinson R: The medical Crisis that's aggravating Iraq's unrest. A reuters special report. March 2, 2020, Available from: https://www.reuters.com/article/us-iraq-healthspecialreport/special-report-broken-health-the-medical-crisis-
thats-aggravating-iraqs-unrest-idUSKBN20P1QB [Accessed on 20 August 2020]

6. The conversation, How the 2003 Iraq invasion devastated the country's health service. July 6,2016. Available from: https://theconversation.com/how-the-2003-iraq-invasiondevastated-the-countrys-health-service-61972 [Accessed 20 August 2020]

7. United Nation Office on Drugs and Crime. Corruption and Integrity Challenges in the Public Sector of Iraq - An evidencebased study, 2013. Available from https://www.unodc.org/documents/publications/2013_Report_on_ Corruption_and_Integrity_Iraq.pdf [Accessed 20 Aust 2020]

8. Cetorelli V, Shabila NP. Expansion of health facilities in Iraq a decade after the US-led invasion, 2003-2012. Confl Health2014; 8: 16 (2014). https://doi.org/10.1186/1752-1505-8-16

9. Ganasegeran K, Perianayagam W, Abdul Manaf R, Ali Jadoo SA, Al-Dubai SAR. Patient Satisfaction in Malaysia's Busiest Outpatient Medical Care. The Scientific World Journal. Hindawi Limited; 2015; 2015:1-6. Available from: http://dx.doi.org/10.1155/2015/714754

10. Lwanga SA, Lemshow S. Sample Size Determination in Health Studies: A PracticalManual, WorldHealth Organization, Geneva, Switzerland, 1991.

11. Raosoft, sample size calculator http://www.raosoft.com/samplesize.html?nosurvey.

12. Marshall GN, Hays RD. The Patient Satisfaction Questionnaire Short Form (PSQ-18). Santa Monica, CA: RAND Corporation, 1994. https://www.rand.org/pubs/papers/P7865.html.

13. Ali Jadoo SA, AljunidSM, Seher Nur Sulku, Al-Dubai SAR, Wan Puteh SE, Ahmed Z, Abdul Manaf MR, Sulong SB, Nur AM. Health system reform from the people's point of view: development of reliable and valid questionnaire. Malaysian Journal of Public Health Medicine 2013;13(2):65-76.

14. Tawfik-Shukor A, Khoshnaw H. The impact of health system governance and policy processes on health services in Iraqi Kurdistan. BMC Int Health Hum Rights 10, 14 (2010). https://doi.org/10.1186/1472-698X-10-14

15. Ali Jadoo SA, Sarhan Y, Al-Samarrai M, Al-Taha M, AL- Any B, Soofi A, Yahyaa B, Al-Rawi R. The impact of displacement on the social, economic and health situation on a sample of internally displaced families in Anbar Province, Iraq. Journal of Ideas in Health 2019;2 (1):56-9. https://doi.org/10.47108/jidhealth.Vol2.Iss1.16

16. Al-Samarrai M, AL- Any B, Soofi A, Yahyaa B, Ali Jadoo SA. Impact of internal displacement on psychosocial and health status of students residing in the hostel of Anbar University, Iraq. Journal of Ideas in Health 2020;3(1):140-4. https://doi.org/10.47108/jidhealth.Vol3.Iss1.25

17. Yan Z, Wan D, Li L. Patient satisfaction in two Chinese provinces: Rural and urban differences. Int J Qual Heal Care. 2011; 23(4): 384-389. https://doi.org/10.1093/intqhc/mzr03

18. Henning-Smith C, Prasad S, Casey M, Kozhimannil K, Moscovice I. Rural-Urban Differences in Medicare Quality Scores Persist After Adjusting for Sociodemographic and Environmental Characteristics. Rural Health. 2019; 35(1): 58-67. https://doi.org/10.1111/jrh.12261 
19. Laksono AD, Wulandari RD, Soedirham O. Urban and Rural Disparities in Hospital Utilization among Indonesian Adults. Iran J Public Health. 2019; 48(2): 247-255. https://doi.org/10.18502/ijph. v48i2.819

20. Henning-Smith C, Kozhimannil K, Casey M, Prasad S, Moscovice I. Rural-Urban Differences in Medicare Quality Outcomes and the Impact of Risk Adjustment. Med Care. 2017; 55(9): 823-829. https://doi.org/10.1097/ MLR.0000000000000761

21. Li J, Shi L, Liang H, Ding G, Xu L. Urban-rural disparities in health care utilization among Chinese adults from 1993 to 2011. BMC Health Serv Res. 2018; 18(1): 102. https://doi.org/10.1186/s12913-018-2905-4

22. Yaya S, Bishwajit G, Ekholuenetale M, Shah V, Kadio B, Udenigwe O. Urban-rural difference in satisfaction with primary healthcare services in Ghana. BMC Health Serv Res. 2017; 25; 17(1): 776. https://doi.org/10.1186/s12913-017-2745-7

23. Rahmqvist M, Bara AC. Patient characteristics and quality dimensions related to patient satisfaction. Int $\mathrm{J}$ Qual Heal Care. 2010; 22(2): 86-92. https://doi.org/10.1093/intqhc/mzq009

24. Levinton C, Veillard J, Slutsky A, Brown A. The importance of place of residence in patient satisfaction. Int $\mathrm{J}$ Qual Heal Care. 2011; 23(5): 495-502. https://doi.org/10.1093/intqhc/mzr048

25. Mollica MA, Weaver KE, McNeel TS, Kent EE. Examining urban and rural differences in perceived timeliness of care among cancer patients: A SEER-CAHPS study. Cancer. 2018;124 (15): 32573265. https://doi.org/10.1002/cncr.31541

26. Yahyaa BT, Al-Samarrai MAM, Ali Jadoo SA. Prevalence and perception of women about consanguineous marriage in AlRamadi City. Indian Journal of Public Health Research and Development 2019;10(4): 567-573

27. Loopstra R, Reeves A, Taylor-Robinson D, Barr B, McKee M, Stuckler D. Austerity, sanctions, and the rise of food banks in the UK. BMJ. 2015; 350:1775.
28. 6. da Costa FA, Pedro AR, Teixeira I, Bragança F, da Silva Aranda, José Cabrita J. Primary non-adherence in Portugal: findings and implications. Int J Clin Pharm2015; 37:626-35.

29. Afzal M, Rizvi F, Azad AH, Rajput AM, Khan A, Tariq N. Effect of demographic characteristics on patient's satisfaction with health care facility. J Postgrad Med Inst. 2014;28(2):154-60.

30. Kelly G, Mrengqwa L, Geffen L. "They don't care about us": older people's experiences of primary healthcare in Cape Town, South Africa. BMC Geriatr2019; 19: 98. https://doi.org/10.1186/s12877-019-1116-0

31. Woods SE, Heidari Z. The influence of gender on patient satisfaction. J Gend Specif Med. 2003;6(4):30-35.

32. Chandra S, Ward P, Mohammadnezhad M. Factors associated with patient satisfaction in outpatient department of Suva subdivisional health center, Fiji, 2018: A mixed method study. Front Public Health. 2019; 7:183. https://doi.org/ 10.3389/fpubh.2019.00183.

33. Alkhazrajy LA, khazaal AM. Satisfaction of Iraqi women regarding antenatal care services applied at primary health care centers in Baghdad. International Journal of Current Medical and Pharmaceutical Research 2016; 2 (3): 235-243.

34. Mustafa I, Satar A. Patients' Satisfaction about Health Services in Out-patients Clinics of Teaching Hospitals in Erbil City. Erbil Journal of Nursing and Midwifery2019;2(1): $26 \quad-33$. https://doi.org/10.15218/ejnm.2019.04

35. Al-Ali BA, Al Mousawi A, Hatef ZS, Mohammed HR. Patient's Satisfaction with Primary Health centers in Kerbala City/ Iraq in 2018. Journal of Critical Reviews.2020; 7 (11): 1072-85.

36. Ebrahim SM, Issa SS. Satisfaction with Nursing Care among Patients Attending Oncology Center in Basra City, Iraq. Journal of Environmental Science and Engineering A 4 (2015); 241-248

37. Al-Samarrai MA, Ali Jadoo SA. Iraqi medical students are still planning to leave after graduation. Journal of Ideas in Health 2018;1(1):23-8. 